\title{
INFOGRAPHIC MODELING BASED ON 3D LASER SURVEYING FOR INFORMED UNIVERSAL DESIGN IN ARCHAEOLOGICAL AREAS: THE CASE OF OPPIDUM OF THE ANCIENT CITY OF TUSCULUM
}

\author{
L. Cemoli, S. D’Auria, F. De Silla, S. Pucci, R. M. Strollo* \\ LAboratory of Survey and Architecture - LAREA, Engineering Macroarea \\ University of Rome Tor Vergata, Via del Politecnico 1, Rome, Italy \\ (lacemoli, saverio.d.auria, fabrizio.de.silla)@uniroma2.it; sa.pucci83@gmail.com; strollo@ing.uniroma2.it
}

\author{
Commission II, WG II/4
}

\begin{abstract}
KEY WORDS: Laser scanning, 3D modeling, Universal Design, Natural and architectural barriers, Valorisation, Cultural Heritage
\end{abstract}
\begin{abstract}
:
The valorisation of archaeological sites represents a fundamental action for the social and economic development of a country. An archaeological park is often a territory characterized by significant testimonies of antiquity of great landscape value. For this reason, it should be configured as an authentic outdoor museum, enriched by natural, environmental, architectural and urban components. In order to fulfill these requirements, it is fundamental the elaboration of a coherent scientific project of preservation, fruition and valorisation of the area, which merge the different components necessary for the establishment of an archaeological museum-park. One of the most critical aspects related to the fruition of archaeological sites is the accessibility to areas and routes, not always - if ever - designed for people with reduced mobility, also temporary (for example elderly, obese, visually impaired, etc.). In general, an established principle used in the new design is to pay attention to the so-called wide users, in accordance with the international guidelines summarized in the concept of Universal Design.

In particular, this paper presents the use of three-dimensional models obtained from laser scanning surveys for the design of walking trails for people with reduced mobility in the Tusculum Archaeological-Cultural Park.

The work was based on the fundamental implementation of the three-dimensional survey with terrestrial laser scanning for the construction and the control of the complex morphology of the site, and on the subsequent integration of models of the intervention in the three-dimensional reality "as-built" of the site. The obtained infographic model allowed to study and simulate the impact of the routes for people with reduced mobility, and to verify its efficiency in the historical and landscape context. Moreover, it was possible to verify the construction of other facilities in the real conditions of the site.
\end{abstract}

\section{INTRODUCTION}

The underlying principles of the Universal Design (ensuring accessibility to largest possible number of people, including those with disabilities) are now internationally shared and adopted in the design of urban spaces, public and private buildings. In historical and artistic contexts, this approach encounters various difficulties due to the complex morphology, typical of the archaeological sites, and to design approaches on theoretical-cultural issues such as the inviolability of antiquities. These difficulties are mostly reflected in the overcoming architectural and natural barriers.

The matter, therefore, must be set with balance and with methodological and design strategies which on the one hand do not compromise the organicity and the perception of ancient places, on the other make the cultural heritage accessible: the collective fruition of the monuments is an integral part of a proper work of protection and valorisation over time.

To conciliate the requirements of accessibility with those of the preservation of cultural heritage adds elements of high criticality to an already complicated field. This implies the need of an in-depth knowledge implemented, above all, through the disciplines of Representation. These disciplines, in fact, provide methodologies and processes - even highly technological which are able to determine, throught the survey, morphological, material, physical and structural features of the architecture.

Through the construction of infographic models (two and threedimensional) scientifically valid, the survey can be a powerful tool in order to analize the issues related to Universal Design for historic value, due to making possible, for example, the simulation of the environmental impact on the archaeological context of projects realized to improve their usability.

The main difficulty in the use of an archaeological site is the presence of hard sloping lands and long walking routes characterized by uneven surfaces (irregular pavement, rough terrain, etc.). In this scenario, this work is part of an ongoing research project regarding the digitization of archaeological cultural heritage present in the Tusculum, an area located in the south-east of Rome.

The aim of this project is to create an open database for the documentation and the virtual use of the monuments present in this area, complemented with historical research, iconographic documents and archives.

Taking advantage of the latest methodologies and technologies of three-dimensional survey and the potential offered by the ICT fields, significant positive effects are expected on the scientific research, cataloguing, preservation, conservation, valorisation and especially on the fruition of this important archaeological site.

\footnotetext{
* Corresponding author
} 


\section{ARCHAEOLOGICAL-CULTURAL PARK OF TUSCULUM}

Tuscolo was an ancient town hall that was built before Rome, probably with the involvement of the Etruscans; it was involved in the Latin League and the city made alliance with the Romans. After the collapse of the Empire and the following period characterized by barbarian invasions, the city had a gradual recovery in the 9th century becoming the stronghold of the powerful family of the Counts of Tuscolo. These, in contrast with the Church, were than defeated and the city was destroyed by troops of Pope Celestine III in 1191.

Tuscolo became universally known, in modern age, thanks to the Tuscolanae Disputationes, the philosophical conversations written in the middle of the first century BC. by Marco Tullio Cicero in his villa on the Tuscolan hills in the southeast of Rome, so called in reference to the ancient city.

From Humanism, in the context of the Renaissance rediscovery of classics, there was an interest in the search for the ancient location of the city. Only in the first quarter of the nineteenth century, archaeologists Antonio Nibby and Luigi Biondi discovered the correctposition of Tuscolo. In the past it was also confused with the modern Frascati, which rised more downstream. Immediately it was clear the urban articulation defined by a vast oppidum closed by an arx, that blend perfectly with the orography of the place.

The site became an object of interest not only for many archeologists but also for designers: travelers, engravers, photographers, vedutists and architects who realized representations or reconstructions often imaginative, such as those of Tony Garnier (Figs. 1-2).

The first scientific survey can be dated in the early years of 20th, made by Regia Scuola degli Ingegneri di Roma (Fig. 3). Particularly, the attention of scholars was concentrated in the eastern area of oppidum, near the acropolis where the forum in the city was identified, marked by the presence of the theater. The first construction phase, of the three identified by archaeologists, is referred to the middle of the first century BC, while the maximum development is attributed to the intermediate phase, in the Julius Claudia age (first half of the 1st century AD).

The remains of the theater show a peculiarity which was never found in the building type: a road crosses the base of the building, called via tecta.

In addition, the theater has also become a symbol of Tuscolo because, in the last two decades, it has brought back to its original function as a location for shows.

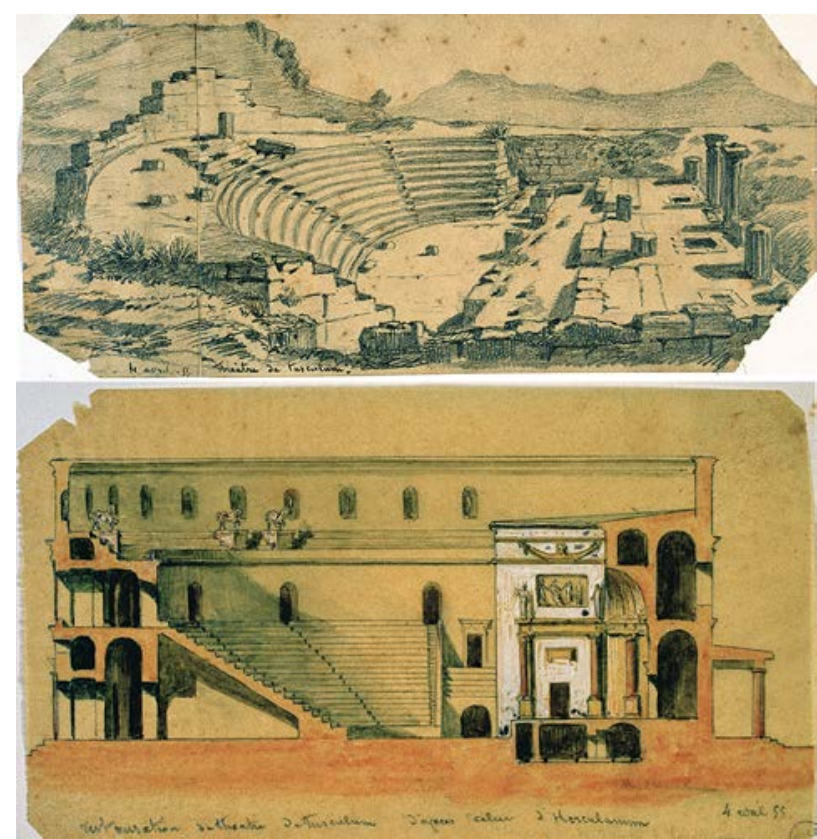

Figure 1. Two freehand drawings by Maurice Sand dated April 4, 1855. Perspective view of the theater (top); reconstructive section of the theater (bottom), based on the theater of Herculaneum

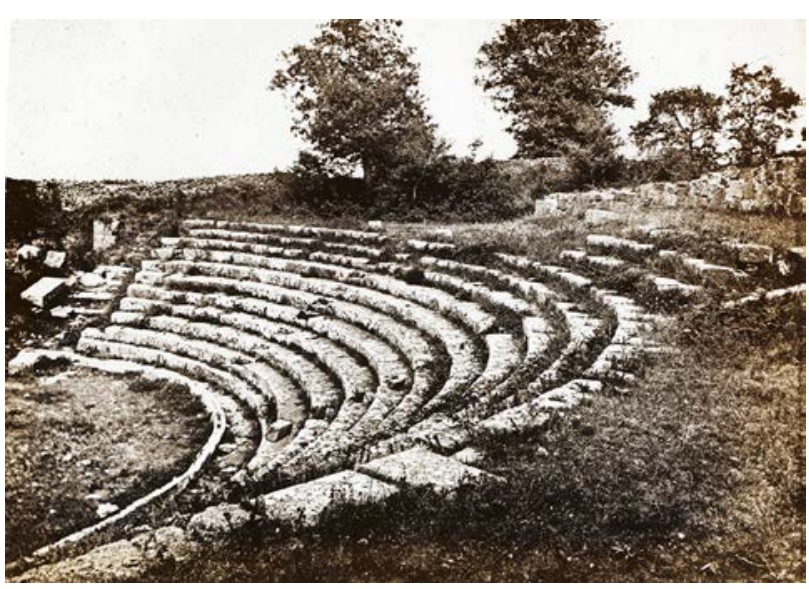

Figure 2. One of the first photographic reproductions of the theater of Tuscolo: John Henry Parker (second half of the 19th century)

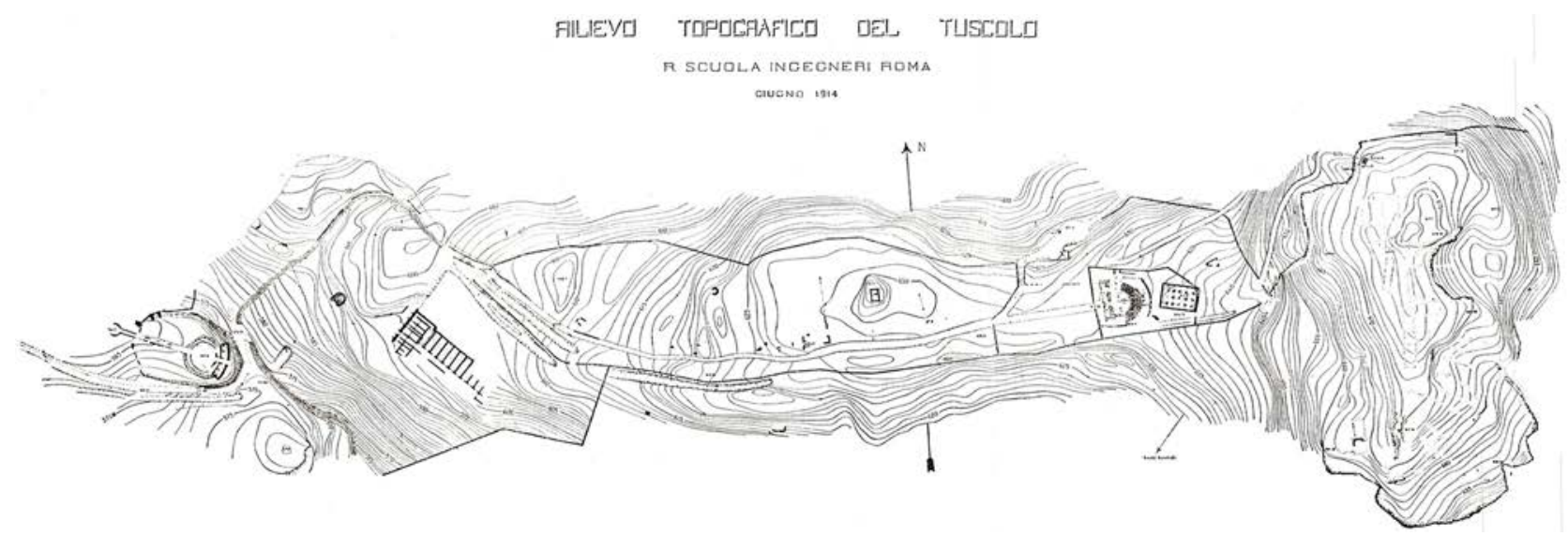

Figure 3. One of the first topographic surveys of the Tuscolo realized in June 1914 by the R. Scuola Ingegneri Roma 
The survey, the digital modeling, the graphic representation and the realistic simulations of the area serve a double purpose. The first is the documentation aimed to knowledge, the second is related to the possible actions to its usability.

\section{SURVEY AND DATA POST-PROCESSING}

In order to assume hypotheses which are appropriate in sensitive contexts, such as archaeological areas, a conscious control of the geometry represents a crucial aspect. Therefore, an integrated methodology with the use of laser scanner and total station is applied in this research to investigate the eastern part of Tusculum oppidum.

\subsection{Topographic survey}

The topographic survey was necessary to obtain accurate results in the phase of the point-clouds alignment to consider point by point the exact layout of some walking trails and to create a single reference system for any possible subsequent integrations.

In the preliminary planning phase, the basic frame-work of control points (also called stations) were first identified for a correct and complete survey of this archaeological area. In particular, a closed polygonal network was defined using 3 control points located at the beginning of via tecta, in the upper part of the theatre and nearby the remains of some religious buildings located at the entrance of the archaeological area (Fig. 4).

The equipment used to perform the survey was the total station SOKKIA SET530RK3, that allowed to acquire threedimensional coordinates for 64 points (planar high-contrast targets and characteristic points of the archaeological area).

The data editing phase was carried out in Leonardo Xpress. The coordinates of the target points were processed both in text format, for the subsequent implementation in point-clouds management software, and in CAD vector format. The latter was used for operating a dimensional control in the modeling and graphic restitution.

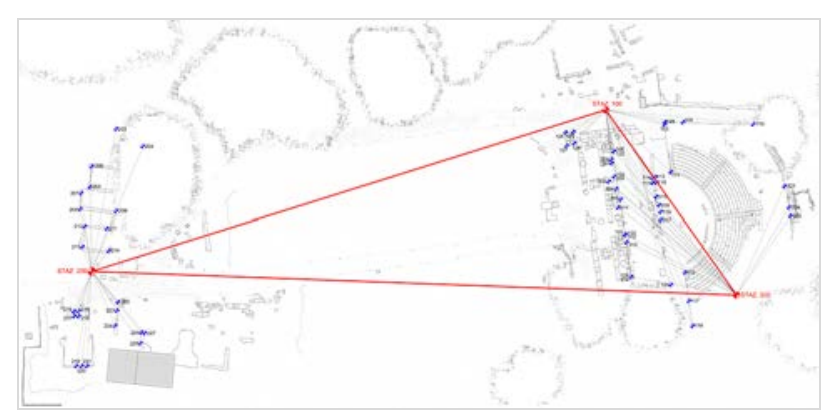

Figure 4. Topographic survey with total station

\subsection{Laser scanning and processing of point clouds}

The survey of this large territory, covering an area of two hectares, comprising the remains of the theater, a part of the historic via tecta and a few sacred buildings, was carried out using laser scanning.

This methodology was preferred to other ones, for example to aerial photogrammetry, because the metric measurements obtained are more accurate and complete and the dense vegetation is an impediment to the UAV flight.

The advantages of laser scanner are well suited for the study of the orography of the area, preparatory phase to the design of tourist trails on archaeological remains. For this work the laser Faro Focus ${ }^{3 \mathrm{D}}$ X130 was chosen. It was setted to obtain a points resolution of $1 / 5$ (one point per 8 millimeters to ten meters), a 3X quality and RGB color with image sensor active. The number of scans, thirty in all, was determined by the need to obtain an accurate model of the surfaces with no significant information gaps.

During the acquisition step were used both checkerboard target, applied to the vertical surfaces, and spherical target as well, in order to facilitate the subsequent phase of the data postprocessing. In this way, they were included in each scan also the elements of reference useful to the union of the scans themselves (Fig. 5).

Faro Scene software was implemented for the post-processing step of the data. The pre-alignment and registration of the scans were carried out with well-established procedures and algorithms of alignment, filtering and noise reduction. The final output is a 3D point clouds with a final scan point tension of 3.7 millimetres. This value is acceptable for the objectives pursued by this research (Fig. 6).

Through this database users can inspect at any time all different elements of the 3D model of a complex site (from the morphological, historical and artistic points of view), minimizing the chances of mistakes. Furthermore, the model can also be metrically, geometrically and colorimetrically interrogated. It was useful to perform, directly on the threedimensional replication of the area, the analysis to improve availability and accessibility according the principles of Universal Design.

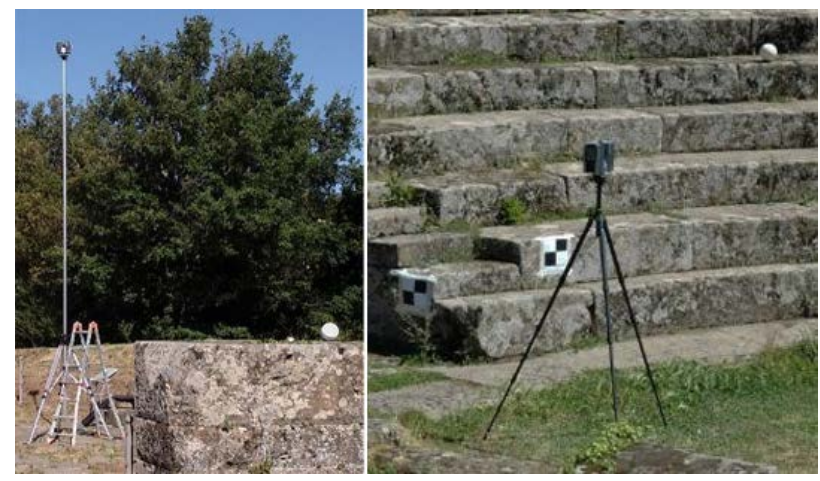

Figure 5. Some laser scanning stations with the use of spherical and chessboard targets

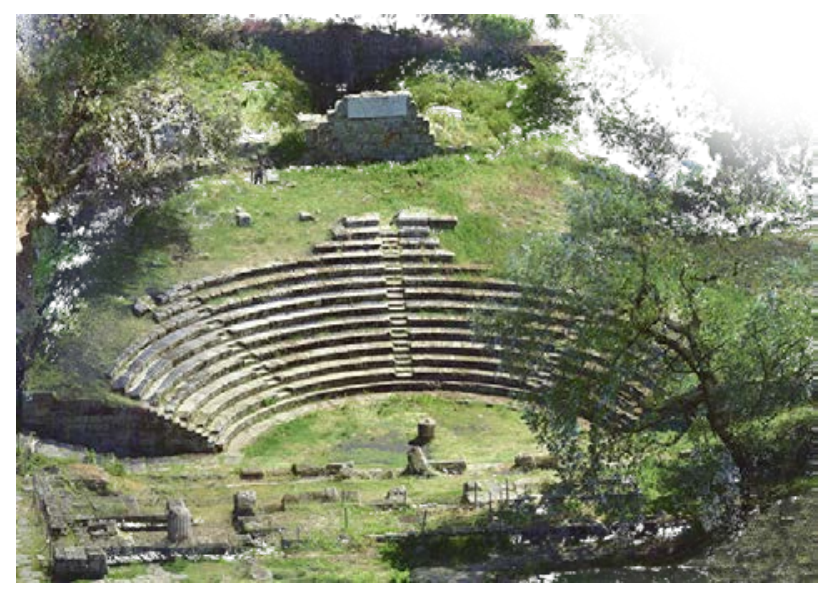

Figure 6. Point clouds model of the Theater 


\subsection{Mesh modeling for design}

In addition to the classic two-dimensional graphics, to allow a careful design and then to evaluate the different project hypotheses, a three-dimensional model was also realized, consisting of triangular meshes. Moreover, this model allowed to check point by point, and at any time, the geometry and the morphology which characterize the archaeological site.

The transformation from point clouds to continuous surface was conducted using the software Geomagic Studio. In order to manage the high amount of data of the point clouds model, and obtain a reasonable approximation of the reality, the full 3D model was divided into three portions. For each of these, an overlap surface was provided to resolve the interpolation problems that are generated at the boundary during the conversion from scan points to mesh. Each part was converted to a continuous surface individually, and only subsequently reassembled in a single model. In particular, the following portions were considered: the first corresponded to the ruins of the religious buildings located near the entrance of the site, the second one was comprised between the internal paths and surrounding ground and the last one was in correspondence with the theatre and via tecta.

For each cloud portion, decimation and data optimization filters were applied assuring the desired conversion quality. In particular, a higher decimation of scanning points was performed for the intermediate portion since the planoaltimetric variations of the terrain were less complex and required less polygons for their description. These operations were carried out in order to get a lighter model.

Once obtained it, the partial mesh models were re-assembled together and the gaps between them were closed and modelled (Fig. 7). This model was used for rendering to assess and simulate the environmental and landscape impact of possible design solutions (Fig. 8).

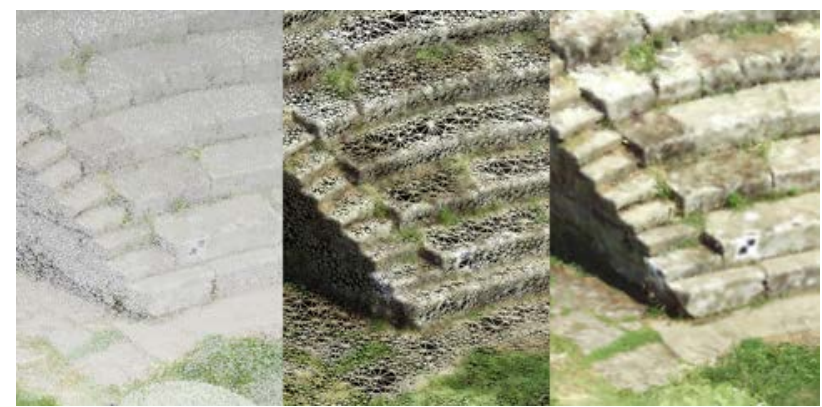

Figure 7. From point clouds (left) to mesh model (right)

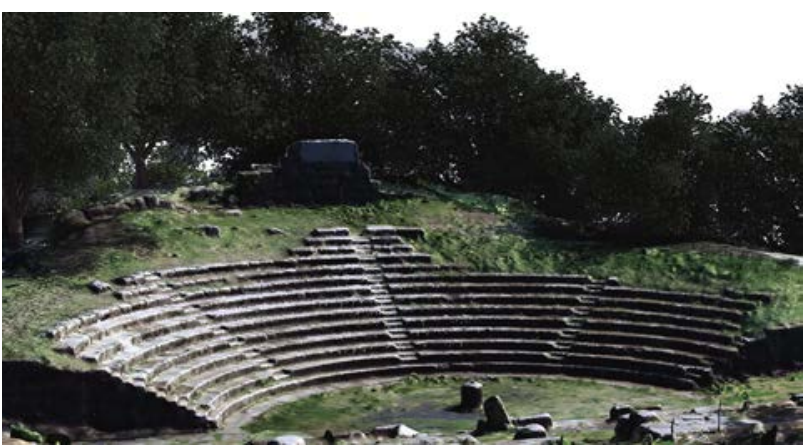

Figure 8. Render obtained from mesh model

\subsection{D drawings from 3D survey}

Using the point cloud of the site was obtained graphic restitution of the plan views and of the horizontal and vertical sections useful for the project, complete with colour data in projection, after having imported the 3D model into a CAD software. This methodology allows to by-pass the complicated and long phase of selection of what we have to survey and represent, as occurs in a traditional survey.

Within the workflow (Fig. 9), was converted point clouds from Faro Scene (.lsproj) to an Autodesk ReCap 360 Pro project (.rcp); after having verified that the requirements set out at the beginning have been met: that no data loss has occurred and the error of alignment shall not exceed the maximum tolerable error value. The .rcp project was than imported in Autodesk AutoCAD.

In this way, hardware performance have been optimized to allow easier and faster menagement of the model in Autodesk AutoCAD (Fig. 10, next page).

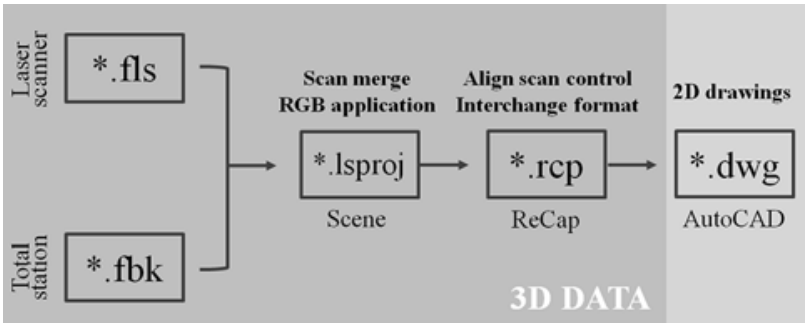

Figure 9. Workflow

\section{DESIGN AND MODELING OF ACCESSIBILITY}

Rough lands, slopes above 8\% and emerging archaeological remains are the most criticalities of the Park's routes. The project hypotheses, inspired by the archaeological contexts of the Market of Trajan in Rome and Pompeii, are to develop a route linking the main entrance to the theater. Thanks to the point clouds and the mesh models, it was possible to locally analyze the criticalities of the project, foreseeing, first of all, the ground compacting and the installation of ischiatic supports and seating systems.

The access and the visit to the theater are facilitated by the installation of a removable pedestrian platform system, statically autonomous and non-invasive in relation to the context in which they are fitted. The system consists of ramps, walkways, protective parapets and an elevating platform, indispensable for the crossing of the ruins of the proscaenium and of the difference in height for the arrival in the orchestra. It consists of a wooden stage accessible through two side ramps. The project also envisages the integration of the lost cavea steps both to increase the number of seats and to make practicable the uphill and the downhill.

All structures are designed in corten steel and wood which allow to form formally and chromatically congruent manufacts with the elements of the site. The use of metal also allows to realize less invasive structures from a perceptive point of view, while the alternation of wooden boards and grills in the walkways allows to see thtough the underlying remains. There are also a clear signs which is easily recognizable by visually impaired and tactile information boards for blind people.

All the designs were modeled three-dimensionally in Autodesk AutoCAD and Trimble SketchUp Pro and then implemented in Autodesk 3ds Max to contextualize them in the mesh model of the archaeological area. 


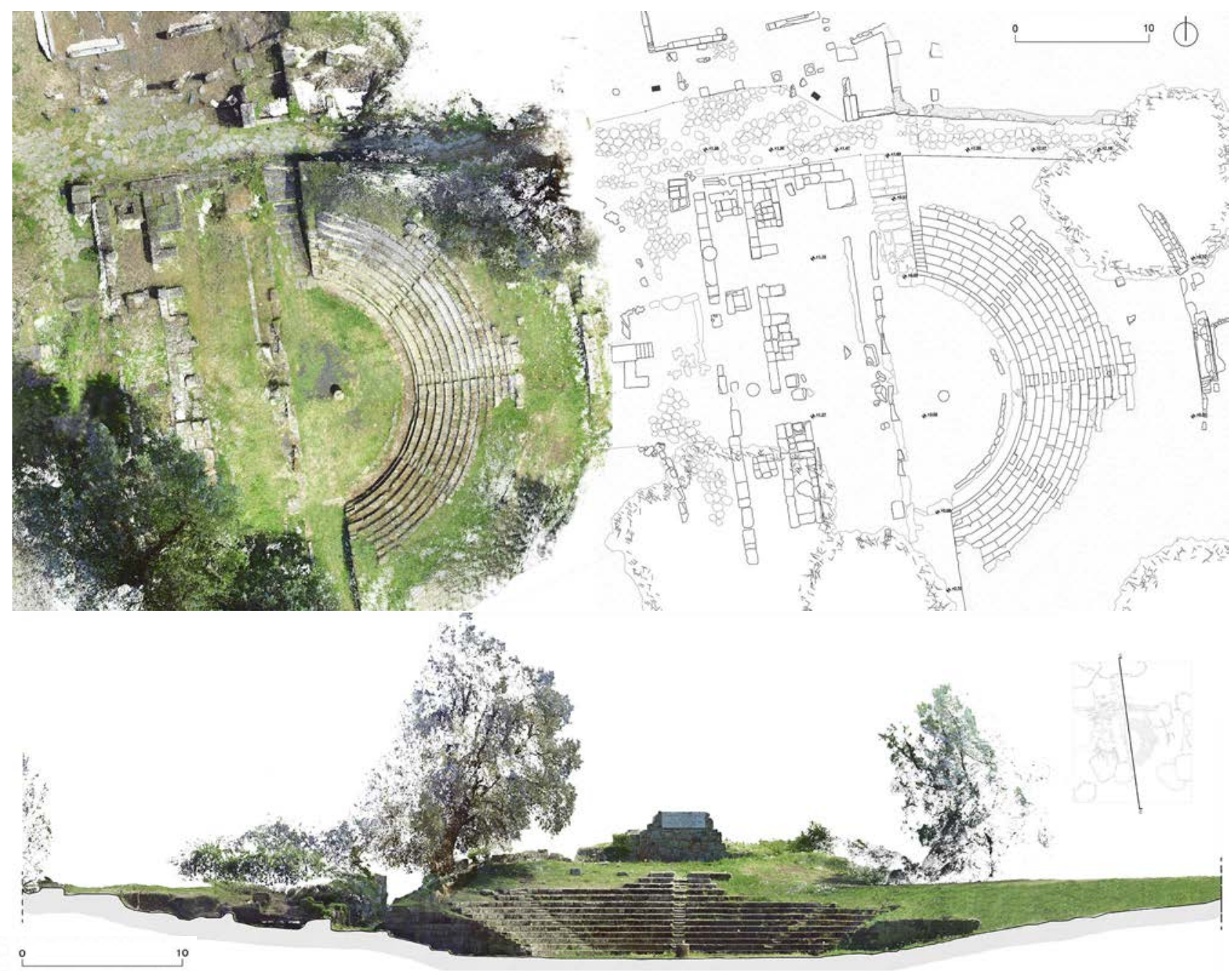

Figure 10. Plan views from point cloud (top-left) and vectorization (top-right), orthoimage of front section from point cloud (bottom).

The realization of photorealistic rendering, prospective views and virtual tours (Fig. 11) has allowed to simulate the architectural impact of the works designed in the archaeological-landscaping context of the Park.

\section{CONCLUSIONS}

The approach to Universal Design for archaeological areas is a current issue, with complex implications especially for the cultural and social spheres involved.

The research has shown that design analyses, aimed at assuring maximum accessibility of ancient sites, and the indispensable historical-archaeological studies can be effectively supported by 3D models of reality, obtained from surveys scientifically conducted.

Laser scanning, in addition to the well-known and undisputed potential offered in the fields of scientific research on cultural heritage (and not only), allows to manage a reliable database (the point clouds) rich in information about morphology and colorimetric aspects of artefacts and landscapes.

Point clouds and mesh models realized in this way, as soon, can represent key-tools also in designing interventions on cultural heritage.
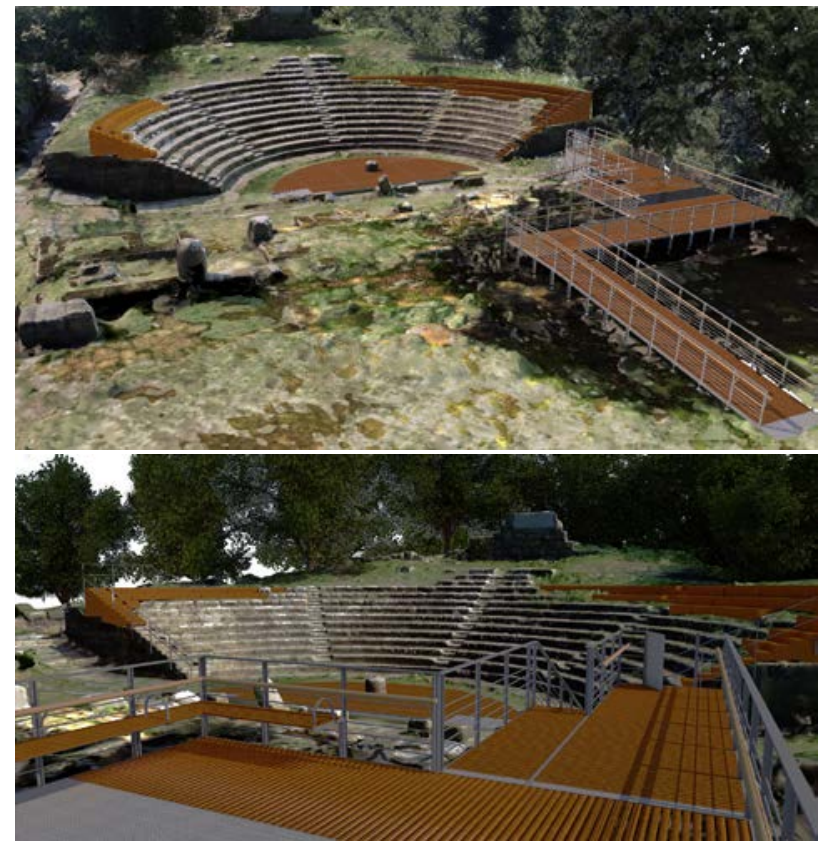

Figure 11. Some render obtained by integrating the survey mesh model and the solid design model 
The possibility of analyzing the complex reality, at any time and from remote location, with a high level of precision and in its entirety, allows to test different project hypotheses. In the way it is also possible to verify architectural-archaeological impacts on the site by integration with other types of $3 \mathrm{~d}$ models and to 'prove', already in the preliminary phase, the functionality of the chosen project.

\section{ACKNOWLEDGEMENTS}

Thanks to Parco Archeologico Culturale di Tuscolo for the availability, to Accademia Vivarium Novum, Claudio Baldoni, Maria Emanuela Bruni, Maria Pia Ciocci, Emanuela De Feo, Roberto Di Maccio, Arturo Gallozzi, Mariachiara Gianfelice and Giuseppe Monti for the cooperation.

Although the paper is the result of a joint research, each author focused on a specific activity and drew up the following paragraphs: R.M. Strollo, 1. Introduction and 2. Archaeological Cultural Park of Tusculum; F. De Silla, 3.1 Topographic survey and 3.3 Mesh modeling for design; S. D'Auria, 3.2 Laser scanning and processing of point clouds, $3.42 \mathrm{D}$ drawings from $3 D$ survey and 5. Conclusions; L. Cemoli and S. Pucci, 4. Design and modeling of accessibility.

\section{REFERENCES}

Cigola, M., et al., 2016. The archaeological site of casinum in Roman era. The reasons for a course of study and knowledge among an urban and archaelogical context. In: Bertocci, S. and Bini, M. (ed.), Proceedings of the XXXVIII International Conference of Professors of Disciplines of Representation, UID,15-17 settembre, Gangemi, Firenze, Italia, pp. 201-208.

D'Auria, S., De Silla, F., Gabrielli, R., Strollo, R.M., 2015. Tecniche di rilievo integrate per la fruizione virtuale di architetture monumentali complesse. Il caso del Ninfeo di Villa Mondragone. In: Archeomatica, Vol. 4, a. VI, mediaGEO, Roma, Italia, pp. 36-40.

Dupré Raventós, X., 2007. Il Teatro tardorepubblicano di Tusculum. Cronologia e trasformazioni. In: Scienze dell'Antichità, n. 12, 2004-2005, Atti del Convegno Il Teatro Romano di Terracina e il Teatro Romano nell'Antichità, Quasar, Roma, Italia, pp. 23-39.

Empler, T., 2013. Design: the role of Drawing and Survey. In: Disegnare idee immagini, Gangemi, Roma, Italia, Vol. 43, pp. 52-63.

Fiasconaro, V. and Guiducci, S., 2011. Realizzazione di un Prototipo di Realtà aumentata applicato ai siti archeologici. In: Bordoni, L. (ed.), Proceedings of AI \& Cultural Heritage Workshop, ENEA, Roma, Italia, pp. 39-47.

Gonizzi Barsanti, S., Remondino, F., Visintini, D., 2013. 3d surveying and modeling of archaeological sites. Some critical issues. In: The International Archives of the Photogrammetry, Remote Sensing and Spatial Information Sciences, Vol. II5/W1, pp. 145-150.

Guidia, G., Russo, M., Angheleddua, D., 2014. 3D survey and virtual reconstruction of archeological sites. In: Digital
Applications in Archaeology and Cultural Heritage, Vol. 1, n. 2, pp. 55-69.

Ippoliti, E. and Meschini, A., 2011. La “scena 3D” per la valorizzazione del patrimonio culturale architettonico e urbano: piazza Arringo ad Ascoli Piceno. In: Gambardella, C. (ed.), Proceedings of the IX Internazional Forum Le vie dei Mercanti. S.A.V.E. Heritage - Safeguard of Architectural, Visual, Environmental Heritage, La scuola di Pitagora, Napoli, Italia, pp. 1-10.

Labadi, S., 2013. UNESCO, Cultural Heritage, and Outstanding Universal Value: Value-based Analyses of the World Heritage and Intangible Cultural Heritage Conventions. AltaMira Press, Lanham, MD, USA, p. 204.

Milgram, P. and Kishino, F., 1994. A Taxonomy of Mixed Reality Visual Displays. In: IEICE Transactions Information Systems, Vol. E77-D, n. 12, pp. 1321-1329.

Remondino, F., 2003. From point cloud to surface: the modeling and visualization problem. In: The International Archives of the Photogrammetry, Remote Sensing and Spatial Information Sciences, Vol. XXXIV-5/W10, p. 11.

Sheppard S.R.J., 2004. Laser-scanning for landscape planning: implications for policy and practice from an end-user's perspective. In: The International Archives of the Photogrammetry, Remote Sensing and Spatial Information Sciences, Vol. XXXVI-8/W2, p. 10.

Zerbi, A., et al., 2016. Il restauro virtuale della ex-cappella ducale di San Ludovico a Parma. In: DISEGNARECON, Bologna, Italia, Vol. 9, n. 17, p. 10. 